\title{
Animal Models for Panic Disorder
}

Sueslene Prado Rocha ${ }^{1}$, Rhayra Xavier do Carmo Silva ${ }^{2,3,4}$, Anderson Manoel Herculano ${ }^{3}$, Monica Gomes Lima-Maximino ${ }^{1}$, Caio Maximino ${ }^{4}$

1 - Laboratório de Neurofarmacologia e Biofísica, Universidade do Estado do Pará, Campus VIII - Marabá/PA, Brazil

2 - Programa de Pós-graduação em Neurociências e Biologia Celular, Universidade Federal do Pará - Marabá/PA, Brazil

3 - Laboratório de Neurofarmacologia Experimental, Universidade Federal do Pará Marabá/PA, Brazil

4 - Laboratório de Neurociências e Comportamento "Frederico Guilherme Graeff", Universidade Federal do Sul e Sudeste do Pará - Marabá/PA, Brazil

\begin{abstract}
Panic disorder (PD) is characterized by recurrent and unexpected panic attacks associated with behavioral changes and/or persistent anxiety due to the attacks. The development of behavioral models in animals is important for the understanding of the psychobiological and behavioral bases of PD. The present article reviews the main models used in the current literature. The elevated T-maze, used in rats, presents good predictive validity, but its face validity has been questioned. Models using electrical stimulation of the periaqueductal gray present good face validity, but lesser construct validity. Models relying on predator exposure present good predictive and construct validity. These three approaches seek coherence with theories on PD as a way to increase its translational potential; thus, while the elevated T-maze is supported by the Deakin/Graeff theory, the mouse defense test battery relies on the concept of defensive
\end{abstract}


distance, and periaqueductal gray stimulation is based on the functional neuroanatomy of PD. Moreover, to higher or lower degree the three models are supported by an "etho-experimental" approach, with careful observation of animal behavior as a way of discriminating different defensive strategies that model different aspects of anxiety, fear, and panic. Finally, an alternative/complementary model is proposed that uses zebrafish alarm reaction to study this disorder.

Keywords: Panic disorder; Animal experimentation; Defensive behavior (Animal); Escape behavior (Animal)

\section{Introduction}

Panic disorder (PD) is characterized by recurrent and unexpected panic attacks that are associated with behavioral changes and/or persistent anticipatory anxiety due to these attacks (American Psychiatric Association, 2013). Panic attacks occur spontaneously, but there is evidence that, for the majority of patients, moderate phobic or hypochondriac symptoms precede the attacks (Craske, Miller, Rotunda, \& Barlow, 1990; Fava, Grandi, \& Canestrari, 1988); it was proposed, then, that panic attacks are "unpredictable" rather than "unexpected" (Barlow, 2002). Besides symptom phenomenology, PD differs from other anxiety disorders due to its particular pharmacological response (Donald F Klein, 1964, 1981) and, partially, due to the independent structure of genetic and environmental risk factors (Gratacòs et al., 2007).

From a neuroanatomical point of view, PD presents important relationships with circuits underlying fear, including different amygdala nuclei, insular cortex, anterior cingulate cortex, and periaqueductal gray area (PAG) (Graeff \& Del-Ben, 2008; Lovick, 2000). The mechanisms associated with unconditional and conditional responses compose a fight/flight/freeze or aversive brain system that is represented by the medial hypothalamus, several amygdalar 
subnuclei, and the dorsal periaqueductal gray area (dPAG) (Brandão, Anseloni, Pandóssio, De Araújo, \& Castilho, 1999; Canteras, 2002; Cezario, Ribeiro-Barbosa, Baldo, \& Canteras, 2008; Gross \& Canteras, 2012; LeDoux, 2003a; LeDoux \& Pine, 2016; Sukikara, Mota-ortiz, Baldo, Felício, \& Canteras, 2006). The electrical stimulation of these areas elicits a response pattern that characterize what is usually termed a defense reaction, and usually accompanies aversive subjective states characteristic of fear and anxiety (Brandão, Troncoso, Silva, \& Huston, 2003). The functioning of this aversive brain system can also be related to panic attacks. The electrical stimulation of dPAG elicits behaviours similar to the defense reaction as well as ubjective and neurovegetative phenomena that resemble a panic attack not only in experimental animals, but also in humans (Graeff \& Del-Ben, 2008; Graeff, Silveira, Nogueira, Audi, \& Oliveira, 1993; Jenck, Moreau, \& Martin, 1995; Lovick, 2000).

An important concept that organizes theories derived from animal models is that of defensive direction and defensive distance (or predatory imminence continuum) (Deakin \& Graeff, 1991; Fanselow \& Lester, 1988; McNaughton \& Corr, 2004; Perusini \& Fanselow, 2015). In general, it can be said that the more caudal portions of the system (especially the PAG) directly and immediately control defensive responses when the defensive distance is very small (proximal threat). As the distance increases, more complex defensive strategies emerge, and those responses are controlled by progressively more rostral structures, with the cingulate cortex representing the most distal threat. Defensive avoidance ("fear") is controlled by the amygdala and the anterior cingulate (Dresler et al., 2013; McNaughton \& Corr, 2004). Defensive approach (“anxiety”) occurs when a strong drive conflicts with avoidance, triggering risk assessment behavior; these patterns are controlled by septo-hippocampal system and posterior cingulate (R. J. Blanchard \& Blanchard, 1988; Deakin \& Graeff, 1991; Gray \& McNaughton, 2000; LeDoux, 1998a). 


\section{Animal models for panic disorder}

The development of animal models for panic disorder is needed to establish the psychological and biological bases of this disorder, as well as to allow the development of novel therapeutics. Differently from models for generalized anxiety - that present a myriad of formats and exploit a diversity of different behaviors (Belzung \& Lemoine, 2011; Griebel \& Holmes, 2013) -, few paradigms explicitly model PD. The distinction between models for PD and models for generalized anxiety is based mainly on reference to the theoretical constructs that support the models (McNaughton \& Zangrossi Jr, 2008): while tests for generalized anxiety use situations that impose approach/avoidance conflicts to animals - generating behavioral inhibition and risk assessment responses -, models that are relevant for PD are based on defensive responses elicited by aversive stimuli or by the stimulation of specific brain regions (Moreira et al., 2013). In rodents, four main strategies are used to model panic attacks and/or PD: conditional fear responses (fear conditioning), mouse defense test battery, and electrical stimulation of the periaqueductal gray and/or medial hypothalamus (Moreira et al., 2013).

\subsection{Fear conditioning}

Conditional fear responses have been widely used to establish fear-like responses and to elucidate the neural bases of these responses (LeDoux, 1998b, 2003b; Schafe, Nader, Blair, \& LeDoux, 2001). In fear conditioning, animals learn to associate a previously neutral stimulus (CS) with an aversive unconditioned stimulus (US, such as an electrical shock (Pavlov, 1927). In cued fear conditioning, the CS is explicit and reliably predicts the US, acting as a cue or signal; in contextual fear conditioning, animals display a defensive reaction (usually freezing) when introduced to a context (e.g., apparatus or chamber) in which they have been previously 
exposed to the US, and therefore the context represents a complex CS (Davis, Walker, Miles, \& Grillon, 2009). Typically, rats and mice display a initial activity burst to the footshock followed by freezing (LeDoux, 1998b); reexposure to the CS in the absence of the US triggers memory retrieval, which initiates reconsolidation and extinction processes.

While fear conditioning is adaptive, and although conditioning accounts of panic disorder have been widely criticized, this process is an integral part of contemporary learning explanations of PD that attempt to incorporate some complexities of contemporary learning theory . Moreover, these learning accounts of PD provide a compelling explanation for the persistence of PD, in spite of not always being able to explain the etiology of these disorders. Bouton et al. (2001) have argued that panic attacks are salient aversive USs during which feeligs of anxiety and fear can be associated with external and/or interoceptive cues that are present during the attacks; subsequent exposure to these cues can trigger feelings of anticipatory anxiety, which in its turn can exacerbate the next panic attack.

Enhanced fear conditioning has been associated with gene variants in rodent orthologues of human PD risk genes. For example, Tmem132d has been recently found to be associated in murine fear conditioning in a quantitative trait loci panel (Knoll, Halladay, Holmes, \& Levitt, 2016), and female mice with humanized COMT Val158Met polymorphism show reduced contextual fear, increased cued fear, and reduced extinction recall (Risbrough, Ji, Hauger, \& Zhou, 2014). Both genes have variants which increase the risk for PD in humans (Howe et al., 2015). A role for serotonin (5-HT) has also been suggested in conditional fear processes (Homberg, 2012): acute treatment with selective 5-HT reuptake inhibitors (SSRIs) facilitates fear conditioning, reduces contextual fear, and increases cued fear; $5-\mathrm{HT}_{1 \mathrm{~A}}$ receptors inhibit the acquisition and expression of contextual fear; $5-\mathrm{HT}_{2 \mathrm{~A}}$ receptors facilitate the consolidation of cued and contextual fear, while 5- $\mathrm{HT}_{2 \mathrm{C}}$ receptors inhibit the retrieval of cued fear. Therefore, 
5-HT appears to exert opposite effects on contextual and cued fear (Homberg, 2012). While consistent with the idea that contextual fear is more related to anxiety than fear, these results are actually opposed to what is observed in other models (Table 1).

\begin{tabular}{|c|c|c|c|c|}
\hline & SSRIs (acute) & $5-H_{1 A} R$ & $5-H_{2 A} R$ & $5-H_{2} T_{2 C} R$ \\
\hline Cued fear & $\uparrow$ & $?$ & $\uparrow$ & $\downarrow$ \\
\hline Contextual fear & $\downarrow$ & $\downarrow$ & $\uparrow$ & $?$ \\
\hline ETM escape & $\downarrow$ & 0 & 0 & 0 \\
\hline MDTB & 0 & 0 & 0 & 0 \\
\hline PAG stimulation & $\downarrow$ & $\downarrow$ (local injection) & $\downarrow$ (local injection) & 0 (local injection) \\
\hline Zebrafish alarm reaction & $\downarrow$ & 0 & $?$ & $?$ \\
\hline
\end{tabular}

Table 1 - Effect of serotonergic drugs on putative models of fear and panic-like behavior. Abbreviations: ETM: Elevated T-mazed; MDTB: mouse defense test battery; PAG: periaqueductal gray area; SSRIs: selective serotonin reuptake inhibitors.

\subsection{Elevated T-maze}

The elevated T-maze (ETM) is derived from the behavioral model for anxiety that is most widely used contemporaneously - the elevated plus-maze -, and is explicitly based on the Deakin/Greaff hypothesis on the role of 5-HT on defensive behavior (Graeff, Ferreira Netto, \& Zangrossi, 1998; Guimarães, Carobrez, \& Graeff, 2008; Zangrossi Jr \& Graeff, 2014). The 
ETM attempts to explicitly separate defensive behaviors that are evoked by motivational conflict (i.e., behavioral inhibition and risk assessment) from behaviors associated with fear states (i.e., escape). The apparatus consists in two open arms and one closed arm in a perpendicular configuration, elevated $50 \mathrm{~cm}$ from the floor (Viana, Tomaz, \& Graeff, 1994). In a ETM session, the rat executes two tasks: inhibitory avoidance and escape. First, the animal is transferred to the end of the closed arm, and the latency to leave this arm is measured; after 30 s intervals, the task is repeated twice, and increased latency to leave the closed arm is interpreted as the acquisition of inhibitory avoidance (Graeff et al., 1998). After this IA task, the animal is positioned at the end of one of the open arms to measure the escape response (Viana et al., 1994). These two responses - IA and escape - recruit different neuronal circuits (Leite Silveira, Zangrossi, De Barros Viana, Silveira, \& Graeff, 2001) and present opposite 5-HTergic modulation (Graeff, Viana, \& Mora, 1996; Sena et al., 2003; Zangrossi Jr \& Graeff, 2014; Zangrossi Jr et al., 2001; Table 1). IA is interpreted as modeling anxiety-like responses, while escape is interpreted as modeling panic attacks (Graeff et al., 1998). Moreover, the model appears to present good predictive validity for anxiolytic and panicolytic drugs (Graeff et al., 1998). An important critique to the model, however, is its low face validity: the association of escape from the open arm to panic attacks is tenuous, given that the escape observed in the ETM is slow, directed, and controlled - very different from escape responses which are observed in other models (Moreira et al., 2013).

\subsection{Mouse defense test battery}

The mouse defense test battery (MDTB) evaluates the behavior of mice exposed to a natural predator, the rat, at different defensive distances (D. C. Blanchard, Griebel, \& Blanchard, 2001; Yang et al., 2004). The mouse is positioned in an oval runway, and an 
anesthetized rat is manipulated by the experimenter so that its approaches the mouse at a fixed velocity; when the rat approaches the mouse by about $1 \mathrm{~m}$, the mouse usually starts running, attempting to escape the aversive stimulus This model explicitly assumes defensive distance (or predatory imminence continuum) - the psychological distance from the threat (R. J. Blanchard \& Blanchard, 1988; Fanselow \& Lester, 1988) - as a central variable in decision making by the mouse. The model presents excellent predictive validity, since acute treatment with triazolobenzodiazepines and chronic treatment with imipramine, fluoxetine, and moclobemide decrease escape responses, while acute treatment with imipramine and fluoxetine or with panicogenic agents increase escape (D. C. Blanchard et al., 2001). Moreover, facilitating 5-HTergic neurotransmission in the periaqueductal gray inhibits escape in the MDTB (Pobbe, Zangrossi Jr, Blanchard, \& Blanchard, 2011). The model presents as advantages the high ethological relevance, because it uses escape responses in an ecologically valid context and avoids using artificial stimuli such as electric shocks; moreover, the model allows the evaluation of two distinct responses - approach or escape the stimulus - that are predictive of anxiolytic or panicolytic effects, respectively (Moreira et al., 2013).

\subsection{Electrical stimulation of the dIPAG}

The electrical stimulation of the dorsolateral periaqueductal grey (dPAG) evokes abrupt escape and/or freezing behavior and cardiovascular responses that is reminiscent of a panic attack (Beckett \& Marsden, 1995; Brandão, Zanoveli, Ruiz-Martinez, Oliveira, \& LandeiraFernandez, 2008; Schenberg, 2010; Schenberg et al., 2014). Currents with different amplitude, or different concentrations of glutamatergic or nitrergic drugs, are needed to induce freezing and escape (running and jumping) responses (de Oliveira, Del Bel, \& Guimarães, 2001; Schenberg, Bittencourt, Sudré, \& Vargas, 2002; Vianna, Graeff, Brandão, \& Landeira- 
Fernandez, 2001). Usually, lower concentrations or currents elicit alertness and escape, while higher concentrations or currents elicit a sequence that is characterized by alertness, freezing, and escape behavior interspersed with periods of tense immobility (Brandão et al., 2005, 2003, 2008). Similarly, disinhibiting the medial hypothalamus - a diencephalic structure that composes, along with the periaqueductal gray, the encephalic circuits which mediate fear responses and panic attacks (Canteras, 2002) - with GABAergic antagonists promote escape responses, hypertension, and tachycardia (DiMicco, Samuels, Zaretskaia, \& Zaretsky, 2002; Johnson, Lowry, Truitt, \& Shekhar, 2008; Johnson, Truitt, Fitz, Lowry, \& Shekhar, 2008). Both models are based on observations on the effects of electrically stimulating these regions in humans, placing its construct validity in the similarity of neuronal circuits (Moreira et al., 2013); these models also appear to present a good predictive validity, since panicolytic, but not anxiolytic drugs, alter behavior after stimulation (Johnson, Lowry, et al., 2008; Schenberg et al., 2002). However, from an etiological point of view, the induction of responses by direct stimulation of brain regions has a tenuous relation to spontaneous panic attacks observed in humans.

In addition to freezing that is observed during $\mathrm{dPAG}$ stimulation, post-stimulation freezing is also observed (Brandão et al., 2008). Interrupting the electrical stimulation of the $\mathrm{dPAG}$ at the escape threshold elicits this freezing behavior, that is accompanied by activation of the laterodorsal nucleus of the thalamus, suggesting transfer of information to more rostral structures (Brandão et al., 2008). This led Brandão et al. (2008) to speculate that poststimulation freezing is more related to risk assessment, as the animal freezes in order to better accumulate information on threat levels (Hagenaars, Oitzl, \& Roelofs, 2014); as a result, while stimulation-elicited freezing should be treated as a model for a panic attack, post-stimulation freezing would be a better model for anticipatory anxiety in PD (Brandão et al., 2008). 


\subsection{Summary}

All four approaches are heavily based on construct validity, looking for coherence with theories on PD as a way to elevate the translational potential of the model; as such, while the ETM is grounded on the Deakin/Graeff theory, the MDTB is grounded mainly on the concept of defensive distance. Moreover, to a greater or lesser degree, the four models are sustained by an "etho-experimental" approach (R. J. Blanchard \& Blanchard, 1988), based on the careful observation of animal behavior as a way to discriminate between different defensive strategies that model different aspects of anxiety, fear, and panic. The four approaches present important advantages and disadvantages in modeling PD. Given the complexity of PD, it is to be expected that the use of a single model will not mimic all its aspects, withal considering the limitations related to the subjective aspects of the disorder (LeDoux \& Pine, 2016; Pine \& LeDoux, 2017). Using different animal models can mimic different aspects of the disorder, allowing better elucidation of the behavioral and neuropathological underpinnings of the disease. Ideally, various animal models should be used to study the same disorder, including the use of different species (de Mooij-van Malsen, Vinkers, Peterse, Olivier, \& Kas, 2011; Kalueff, Ren-Patterson, LaPorte, \& Murphy, 2008; Kas, Gelegen, Schalkwyk, \& Collier, 2009; van der Staay, 2006).

\section{Complementary models: The alarm response of zebrafish}

Aiming to enrich the breadth of etho-experimental approaches traditionally made with rodents, the use of non-mammalian species has been proposed (Maximino et al., 2015). Among these, zebrafish (Danio rerio Hamilton 1822), a cyprinid fish widely used in genetics and developmental biology, has gained traction as model in behavioral research (Gerlai, 2010; Kalueff et al., 2012; Norton \& Bally-Cuif, 2010; Rinkwitz, Mourrain, \& Becker, 2011; Shams, 
Rihel, Ortiz, \& Gerlai, 2018). Importantly for the study of fear and panic is the range of defensive responses that are observed in this species, among which the alarm reaction is relatively well-characterized and relevant for modeling PD (Gerlai, 2010, 2013; Jesuthasan \& Mathuru, 2008; Maximino et al., 2018; Stewart et al., 2015). This is a response that is initiated in the olfactory system by substances that are released by the damaged skin of conspecifics, and is characterized by dramatic and measurable changes in swimming patterns, as well as in welldefined physiological responses. The "alarm substance" produced by specialized skin cells ("club cells") and released after these cells are damaged is of unknown composition (Døving \& Lastein, 2009; Jesuthasan \& Mathuru, 2008), but it presents hypoxanthine 3- $N$-oxide and chondroitin fragments - substances which mimic part of the behavioral and physiological reactions (Mathuru et al., 2012; Parra, Adrian Jr, \& Gerlai, 2009). During exposure to this substance, an increase in shoal cohesion (Speedie \& Gerlai, 2008) and the initiation of patterns of erratic swimming followed by freezing (Mathuru et al., 2012; Speedie \& Gerlai, 2008) is observed.

Differently from the behavior that is observed during exposure, behavior observed after exposure usually involves increased bottom dwelling associated with erratic swimming and freezing (Cachat et al., 2011; Egan et al., 2009), analgesia (Maximino, 2011), and increased dark preference associated with erratic swimming, freezing, and thigmotaxis (Maximino, Lima, Costa, Guedes, \& Herculano, 2014). Moreover, the alarm substance also produces intense autonomic resposnes, with increased plasma levels of glucose, haemoglobin, norepinephrine, and epinephrine (Maximino et al., 2014), and a neuroendocrine stress response, with increased whole-body cortisol levels (Abreu, Giacomini, Koakoski, Piato, \& Barcellos, 2017; Schirmer, Jesuthasan, \& Mathuru, 2013). This array of behavioral and physiological adjustments simulate some important behavioral aspects and neurovegetative symptoms of panic attacks, lending 
significant face validity to the model. Moreover, the dissociation between responses produced during alarm substance exposure (erratic swimming and freezing, without increased bottom dwelling) and after exposure (increased bottom dwelling, erratic swimming, and freezing) is reminiscent of the distinction between freezing responses during and after the electrical stimulation of the dorsolateral column of the PAG in rats (Brandão et al., 2008), and could be further exploited as dependent variables in models for panic attacks and PD, respectively.

\section{Conclusions}

The animal models reviewed here present different advantages that can be exploited to discover the neurobiological and behavioral mechanisms associated with PD, as well as the specific disadvantages that suggest the use of complementary approaches. These models vary in terms of validity - for example, the face validity of the elevated T maze is lower than the other presented models, but its construct validity is higher than the models involving electrical or chemical stimulation.

Finally, the introduction of new models - including models with non-mammalian species, such as the use of alarm substance in Danio rerio - is an approach with great potential to amplify the field of investigation, testing novel psychobiological, behavioral, and developmental hypotheses on this disorder and associated factors. The field of animal modeling can only profit from the inclusion of these approaches in the roster of investigation strategies.

\section{Acknowledgments}

Part of the research reported was funded by Conselho Nacional de Desenvolvimento Científico e Tecnológico (CNPq/Brazil, grant no. 400726/2016-5). 


\section{References}

Abreu, M. S., Giacomini, A. C. V. V., Koakoski, G., Piato, A. L. S., \& Barcellos, L. J. G. (2017). Divergent effect of fluoxetine on the response to physical or chemical stressors in zebrafish. PeerJ, 5, e3330. https://doi.org/10.7717/peerj.3330

American Psychiatric Association. (2013). Diagnostic and Statistical Manual of Mental Disorders - Fifth Edition - DSM-5 (5th ed.). Washington: American Psychiatric Publishing.

Barlow, D. H. (2002). Anxiety and its disorders. The nature and treatment of anxiety and panic (2nd ed.). New York, NY: The Guilford Press.

Beckett, S., \& Marsden, C. A. (1995). Computer analysis and quantification of periaqueductal grey-induced defence behaviour. Journal of Neuroscience Methods, 58, 157-161.

Belzung, C., \& Lemoine, M. (2011). Criteria of validity for animal models of psychiatric disorders: Focus on anxiety disorders and depression. Biology of Mood \& Anxiety Disorders, 1, 9. https://doi.org/10.1186/2045-5380-1-9

Blanchard, D. C., Griebel, G., \& Blanchard, R. J. (2001). Mouse defensive behaviors: Pharmacological and behavioral assays for anxiety and panic. Neuroscience \& Biobehavioral Reviews, 25, 205-218.

Blanchard, R. J., \& Blanchard, D. C. (1988). Ethoexperimental approaches to the biology of emotion. Annual Review of Psychology, 39, 43-68.

Bouton, M. E., Mineka, S., \& Barlow, D. H. (2001). A modern learning theory on the etiology of panic disorder. Psychological Review, 198, 4-32. 
Brandão, M. L., Anseloni, V. Z., Pandóssio, J. E., De Araújo, J. E., \& Castilho, V. M. (1999). Neurochemical mechanisms of the defensive behavior in the dorsal midbrain. Neuroscience \& Biobehavioral Reviews, 23, 863-875.

Brandão, M. L., Borelli, K. G., Nobre, M. J., Santos, J. M., Albrechet-Souza, L., Oliveira, A. R., \& Martinez, R. C. (2005). Gabaergic regulation of the neural organization of fear in the midbrain tectum. Neuroscience \& Biobehavioral Reviews, 29, 1299-1311. https://doi.org/10.1016/j.neubiorev.2005.04.013

Brandão, M. L., Troncoso, A. C., Silva, M. A. de S., \& Huston, J. P. (2003). The relevance of neuronal substrates of defense in the midbrain tectum to anxiety and stress: Empirical and conceptual considerations. European Journal of Pharmacology, 463, 225-233. https://doi.org/10.1016/S0014-2999(03)01284-6

Brandão, M. L., Zanoveli, J. M., Ruiz-Martinez, R. C., Oliveira, L. C., \& Landeira-Fernandez, J. (2008). Different patterns of freezing behavior organized in the periaqueductal gray of rats: Association with different types of anxiety. Behavioural Brain Research, 188, 1-13. https://doi.org/10.1016/j.bbr.2007.10.018

Cachat, J., Stewart, A., Utterback, E., Hart, P., Gaikwad, S., Wong, K., ... Kalueff, A. V. (2011). Three-dimensional neurophenotyping of adult zebrafish behavior. PLoS ONE, 6, e17597. https://doi.org/10.1371/journal.pone.0017597

Canteras, N. S. (2002). The medial hypothalamic defensive system: Hodological organization and functional implications. Pharmacology, Biochemistry and Behavior, 71, 481-491.

Cezario, A. F., Ribeiro-Barbosa, É. R., Baldo, M. V. C., \& Canteras, N. S. (2008). Hypothalamic sites responding to predator threats - The role of the dorsal premammillary nucleus in unconditioned and conditioned antipredatory defensive behavior. European 
Journal of Neuroscience, 28, 1003-1015. https://doi.org/10.1111/j.14609568.2008.06392.x

Craske, M. G., Miller, P. P., Rotunda, R., \& Barlow, D. H. (1990). A descriptive report of features of initial unexpected panic attacks in minimal and extensive avoiders. Behaviour Research and Therapy, 28, 395-400. https://doi.org/10.1016/0005-7967(90)90158-F

Davis, M., Walker, D. L., Miles, L., \& Grillon, C. (2009). Phasic vs sustained fear in rats and humans: Role of the extended amygdala in fear vs anxiety. Neuropsychopharmacology, 35, 105-135. https://doi.org/10.1038/npp.2009.109

de Mooij-van Malsen, A. J. G., Vinkers, C. H., Peterse, D. P., Olivier, B., \& Kas, M. J. H. (2011). Cross-species behavioural genetics: A starting point for unravelling the neurobiology of human psychiatric disorders. Progress in Neuro-Psychopharmacology \& Biological Psychiatry, 35, 1383-1390. https://doi.org/10.1016/j.pnpbp.2010.10.003

de Oliveira, R. M. W., Del Bel, E. A., \& Guimarães, F. S. (2001). Effects of excitatory amino acids and nitric oxide on flight behavior elicited from the dorsolateral periaqueductal gray. Neuroscience \& Biobehavioral Reviews, 25, 679-685. https://doi.org/S0149763401000501 [pii]

Deakin, J. F. W., \& Graeff, F. G. (1991). 5-HT and mechanisms of defense. Journal of Psychopharmacology, 5, 305-315.

DiMicco, J. A., Samuels, B. C., Zaretskaia, M. V, \& Zaretsky, D. V. (2002). The dorsomedial hypothalamus and the response to stress. Part renaissance, part revolution. Pharmacology, Biochemistry \& Behavior, 71, 469-480. 
Døving, K. B., \& Lastein, S. (2009). The alarm reaction in fishes - Odorants, modulations of responses, neural pathways. Annals of the New York Academy of Sciences, 1170, 413423. https://doi.org/10.1111/j.1749-6632.2009.04111.x

Dresler, T., Guhn, A., Tupak, S. V., Ehlis, A. C., Herrmann, M. J., Fallgatter, A. J., ... Domschke, K. (2013). Revise the revised? New dimensions of the neuroanatomical hypothesis of panic disorder. Journal of Neural Transmission, 120(1), 3-29. https://doi.org/10.1007/s00702-012-0811-1

Egan, R. J., Bergner, C. L., Hart, P. C., Cachat, J. M., Canavello, P. R., Elegante, M. F., ... Kalueff, A. V. (2009). Understanding behavioral and physiological phenotypes of stress and anxiety in zebrafish. Behavioural Brain Research, 205, 38-44. https://doi.org/10.1016/j.bbr.2009.06.022

Fanselow, M. S., \& Lester, L. (1988). A functional behavioristic approach to aversively motivated behavior: Predatory imminence as a determinant of the topography of defensive behavior. In R. C. Bolles \& M. D. Beecher (Eds.), Evolution and Learning (pp. 185-211). Hillsdale: Erlbaum.

Fava, G. A., Grandi, S., \& Canestrari, R. (1988). Prodromal symptoms in panic disorder with agoraphobia. American Journal of Psychiatry, 145, 1564-1567.

Gerlai, R. (2010). Zebrafish antipredatory responses: A future for translational research? Behavioural Brain Research, 207, 223-231. https://doi.org/10.1016/j.bbr.2009.10.008

Gerlai, R. (2013). Antipredatory behavior of zebrafish: Adaptive function and a tool for translational research. Evolutionary Psychology, 11, 591-605. 
Graeff, F. G., \& Del-Ben, C. M. (2008). Neurobiology of panic disorder: From animal models to brain neuroimaging. Neuroscience \& Biobehavioral Reviews, 32, 1326-1335. https://doi.org/10.1016/j.neubiorev.2008.05.017

Graeff, F. G., Ferreira Netto, C., \& Zangrossi, H. (1998). The elevated T-maze as an experimental model of anxiety. Neuroscience \& Biobehavioral Reviews, 23, 237-246. https://doi.org/10.1016/S0149-7634(98)00024-4

Graeff, F. G., Silveira, M. C., Nogueira, R. L., Audi, E. A., \& Oliveira, R. M. (1993). Role of the amygdala and periaqueductal gray in anxiety and panic. Behavioural Brain Research, $58,123-131$.

Graeff, F. G., Viana, M. de B., \& Mora, P. O. (1996). Opposed regulation by dorsal raphe nucleus 5-HT pathways of two types of fear in the elevated T-maze. Pharmacology, Biochemistry and Behavior, 53, 171-177.

Gratacòs, M., Sahún, I., Gallego, X., Amador-Arjona, a, Estivill, X., \& Dierssen, M. (2007). Candidate genes for panic disorder: insight from human and mouse genetic studies. Genes, Brain, and Behavior, 6 Suppl 1, 2-23. https://doi.org/10.1111/j.1601183X.2007.00318.x

Gray, J. A., \& McNaughton, N. (2000). The Neuropsychology of Anxiety: An Enquiry into the Functions of the Septo-Hippocampal System (2a ed.). Oxford: Oxford University Press.

Griebel, G., \& Holmes, A. (2013). 50 years of hurdles and hope in anxiolytic drug discovery. Nature Reviews Drug Discovery, 12, 667-687. https://doi.org/10.1038/nrd4075

Gross, C. T., \& Canteras, N. S. (2012). The many paths to fear. Nature Publishing Group, 13, 651-658. https://doi.org/10.1038/nrn3301 
Guimarães, F. S., Carobrez, A. P., \& Graeff, F. G. (2008). Modulation of anxiety behaviors by 5-HT-interacting drugs. In R. J. Blanchard, D. C. Blanchard, G. Griebel, \& D. J. Nutt (Eds.), Handbook of Anxiety and Fear (pp. 241-268). Amsterdam: Elsevier B. V.

Hagenaars, M. A., Oitzl, M., \& Roelofs, K. (2014). Updating freeze: Aligning animal and human research. Neuroscience \& Biobehavioral Reviews, 47, 165-176. https://doi.org/10.1016/j.neubiorev.2014.07.021

Homberg, J. R. (2012). Serotonergic modulation of conditioned fear. Scientifica, 2012, Article ID 821549. https://doi.org/10.6064/2012/821549

Howe, A., Buttenschøn, H., Bani-Fatemi, A., Maron, E., Otowa, T., Erhardt, A., ... Mors, O. (2015). Candidate genes in panic disorder: Meta-analyses of 23 common variants in major anxiogenic pathways. Molecular Psychiatry, 21, 665-679. https://doi.org/10.1038/mp.2015.138

Jenck, F., Moreau, J.-L., \& Martin, J. R. (1995). Dorsal periaqueductal gray-induced aversion as a simulation of panic anxiety: Elements of face and predictive validity. Psychological Research, 57, 181-191.

Jesuthasan, S. J., \& Mathuru, A. S. (2008). The alarm response in zebrafish: Innate fear in a vertebrate genetic model. Journal of Neurogenetics, 22, 211-229. https://doi.org/10.1080/01677060802298475

Johnson, P. L., Lowry, C. A., Truitt, W., \& Shekhar, A. (2008). Disruption of GABAergic tone in the dorsomedial hypothalamus attenuates responses in a subset of serotonergic neurons in the dorsal raphe nucleus following lactate-induced panic. Journal of Psychopharmacology, 22, 642-652. https://doi.org/10.1177/0269881107082900 
Johnson, P. L., Truitt, W. A., Fitz, S. D., Lowry, C. A., \& Shekhar, A. (2008). Neural pathways underlying lactate-induced panic. Neuropsychopharmacology, 33(9), 20932107. https://doi.org/10.1038/sj.npp.1301621

Kalueff, A. V, Ren-Patterson, R. F., LaPorte, J. L., \& Murphy, D. L. (2008). Domain interplay concept in animal models of neuropsychiatric disorders: A new strategy for high-throughput neurophenotyping research. Behavioural Brain Research, 188, 243249. https://doi.org/10.1016/j.bbr.2007.11.011

Kalueff, A. V, Stewart, A. M., Kyzar, E. J., Cachat, J., Gebhardt, M., Landsman, S., ... Zebrafish Neuroscience Research Consortium. (2012). Time to recognize zebrafish “affective” behavior. Behaviour, 149, 1019-1036. https://doi.org/10.1163/1568539X00003030

Kas, M. J. H., Gelegen, C., Schalkwyk, L. C., \& Collier, D. A. (2009). Interspecies comparisons of functional genetic variations and their implications in neuropsychiatry. American Journal of Medical Genetics, Part B: Neuropsychiatric Genetics, 150, 309317. https://doi.org/10.1002/ajmg.b.30815

Klein, D. F. (1964). Delineation of two drug-responsive anxiety syndromes. Psychopharmacologia, 5, 397-408.

Klein, D. F. (1981). Anxiety reconceptualized. In D. F. Klein \& J. G. Rabkin (Eds.), Anxiety: New Research and Changing Concepts (pp. 235-263). Nova Iorque: Raven Press.

Knoll, A. T., Halladay, L. R., Holmes, A., \& Levitt, P. (2016). Quantitative trait loci and a novel genetic candidate for fear learning. Journal of Neuroscience, 36, 6258-6268. https://doi.org/10.1523/JNEUROSCI.0177-16.2016 
LeDoux, J. E. (1998a). Fear and the brain: Where have we been, and where are we going? Biological Psychiatry, 44, 1229-1238.

LeDoux, J. E. (1998b). Fear and the brain: Where have we been, and where are we going? Biological Psychiatry, 44, 1229-1238.

LeDoux, J. E. (2003a). The emotional brain, fear, and the amygdala. Cellular and Molecular Neurobiology, 23, 727-738.

LeDoux, J. E. (2003b). The emotional brain, fear, and the amygdala. Cellular and Molecular Neurobiology, 23, 727-738.

LeDoux, J. E., \& Pine, D. S. (2016). Using neuroscience to help understand fear and anxiety: A two-system framework. American Journal of Psychiatry, 173, 1083-1093. https://doi.org/10.1176/appi.ajp.2016.16030353

Leite Silveira, M. C., Zangrossi, H., De Barros Viana, M., Silveira, R., \& Graeff, F. G. (2001). Differential expression of Fos protein in the rat brain induced by performance of avoidance or escape in the elevated T-maze. Behavioural Brain Research, 126(1-2), 1321. https://doi.org/10.1016/S0166-4328(01)00233-9

Lovick, T. A. (2000). Panic disorder-A malfunction of multiple transmitter control systems within the midbrain periaqueductal gray matter? Neuroscientist, 6, 48-59.

Mathuru, A. S., Kibat, C., Cheong, W. F., Shui, G., Wenk, M. R., Friedrich, R. W., \& Jesuthasan, S. (2012). Chondroitin fragments are odorants that trigger fear behavior in fish. Current Biology, 22, 538-544. https://doi.org/10.1016/j.cub.2012.01.061 
Maximino, C. (2011). Modulation of nociceptive-like behavior in zebrafish (Danio rerio) by environmental stressors. Psychology \& Neuroscience, 4, 149-155. https://doi.org/10.3922/j.psns.2011.1.017

Maximino, C., Lima, M. G., Costa, C. C., Guedes, I. M. L., \& Herculano, A. M. (2014). Fluoxetine and WAY 100,635 dissociate increases in scototaxis and analgesia induced by conspecific alarm substance in zebrafish (Danio rerio Hamilton 1822). Pharmacology, Biochemistry, and Behavior, 124C, 425-433. https://doi.org/10.1016/j.pbb.2014.07.003

Maximino, C., Silva, R. X. do C., Campos, K. dos S., Oliveira, J. S. de, Rocha, S. P., Pyterson, M. P., ... Maximino, M. L. (2018). Sensory ecology of Ostariophysan alarm substances. Preprints.Org. https://doi.org/10.20944/preprints201803.0279.v1

Maximino, C., Silva, R. X. do C., da Silva, S. de N. S., Rodrigues, L. do S. D. S., Barbosa, H., de Carvalho, T. S., ... Herculano, A. M. (2015). Non-mammalian models in behavioral neuroscience: Consequences for biological psychiatry. Frontiers in Behavioral Neuroscience, 9, Article 233. https://doi.org/10.3389/fnbeh.2015.00233

McNaughton, N., \& Corr, P. J. (2004). A two-dimensional neuropsychology of defense: Fear/anxiety and defensive distance. Neuroscience \& Biobehavioral Reviews, 28, 285305. https://doi.org/10.1016/j.neubiorev.2004.03.005

McNaughton, N., \& Zangrossi Jr, H. (2008). Theoretical approaches to the modeling of anxiety in animals. In R. J. Blanchard, D. C. Blanchard, G. Griebel, \& D. J. Nutt (Eds.), Handbook of Anxiety and Fear (pp. 11-27). Amsterdam: Elsevier B. V. 
Moreira, F. A., Gobira, P. H., Viana, T. G., Vicente, M. A., Zangrossi Jr, H., \& Graeff, F. G. (2013). Modeling panic disorder in rodents. Cell \& Tissue Research. https://doi.org/10.1007/s00441-013-1610-1

Norton, W., \& Bally-Cuif, L. (2010). Adult zebrafish as a model organism for behavioural genetics. BMC Neuroscience, 11, 90. https://doi.org/10.1186/1471-2202-11-90

Parra, K. V, Adrian Jr, J. C., \& Gerlai, R. (2009). The synthetic substance hypoxanthine 3-Noxide elicits alarm reactions in zebrafish (Danio rerio). Behavioural Brain Research, 205, 336-341. https://doi.org/10.1016/j.bbr.2009.06.037

Pavlov, I. P. (1927). Conditioned reflexes. Londres: Oxford University Press.

Perusini, J. N., \& Fanselow, M. S. (2015). Neurobehavioral perspectives on the distinction between fear and anxiety. Learning \& Memory, 22, 417-425. https://doi.org/10.1101/lm.039180.115

Pine, D. S., \& LeDoux, J. E. (2017). Elevating the role of subjective experience in the clinic: Response to Fanselow and Pennington. American Journal of Psychiatry, 174, 11211122. https://doi.org/10.1176/appi.ajp.2017.17070818r

Pobbe, R. L. H., Zangrossi Jr, H., Blanchard, D. C., \& Blanchard, R. J. (2011). Involvement of dorsal raphe nucleus and dorsal periaqueductal gray 5-HT receptors in the modulation of mouse defensive behaviors. European Neuropsychopharmacology, 21, 306-315. https://doi.org/10.1016/j.euroneuro.2010.05.004

Rinkwitz, S., Mourrain, P., \& Becker, T. S. (2011). Zebrafish: An integrative system for neurogenomics and neurosciences. Progress in Neurobiology, 93, 231-243. https://doi.org/10.1016/j.pneurobio.2010.11.003 
Risbrough, V., Ji, B., Hauger, R., \& Zhou, X. (2014). Generation and characterization of humanized mice carrying COMT158 Met/Val Alleles. Neuropsychopharmacology, 39, 1823-1832. https://doi.org/10.1038/npp.2014.29

Schafe, G. E., Nader, K., Blair, H. T., \& LeDoux, J. E. (2001). Memory consolidation of Pavlovian fear conditioning: A cellular and molecular perspective. Trends in Neurosciences, 24, 540-546. https://doi.org/10.1016/S0166-2236(00)01969-X

Schenberg, L. C. (2010). Towards a translational model of panic attack. Psychology \& Neuroscience, 9-37.

Schenberg, L. C., Bittencourt, A. S., Sudré, E. C. M., \& Vargas, L. C. (2002). Modeling panic attacks. Neuroscience \& Biobehavioral Reviews, 25, 647-659. https://doi.org/10.1016/S0149-7634(01)00060-4

Schenberg, L. C., Schimitel, F. G., Armini, R. D. S., Bernabé, C. S., Rosa, C. A., Tufik, S., ... Quintino-dos-Santos, J. W. (2014). Translational approach to studying panic disorder in rats: Hits and misses. Neuroscience \& Biobehavioral Reviews, 46, 472-496. https://doi.org/10.1016/j.neubiorev.2014.10.002

Schirmer, A., Jesuthasan, S., \& Mathuru, A. S. (2013). Tactile stimulation reduces fear in fish. Frontiers in Behavioral Neuroscience, 7, Article 167. https://doi.org/10.3389/fnbeh.2013.00167

Sena, L. M., Bueno, C., Pobbe, R. L. H., de Andrade, T. G. C. S., Zangrossi Jr, H., \& Viana, M. de B. (2003). The dorsal raphe nucleus exerts opposed control on generalized anxiety and panic-related defensive responses in rats. Behavioural Brain Research, 142, 125133. https://doi.org/10.1016/S0166-4328(02)00399-6 
Shams, S., Rihel, J., Ortiz, J. G., \& Gerlai, R. T. (2018). The zebrafish as a promising tool for modeling human brain disorders: A review based upon an IBNS Symposium. Neuroscience \& Biobehavioral Reviews, 75, 176-190.

Speedie, N., \& Gerlai, R. (2008). Alarm substance induced behavioral responses in zebrafish (Danio rerio). Behavioural Brain Research, 188, 168-177. https://doi.org/10.1016/j.bbr.2007.10.031

Stewart, A. M., Ullmann, J. F. P., Norton, W. H. J., Parker, M. O., Brennan, C. H., Gerlai, R., \& Kalueff, A. V. (2015). Molecular psychiatry of zebrafish. Molecular Psychiatry, 20, 2-17. https://doi.org/10.1038/mp.2014.128

Sukikara, M. H., Mota-ortiz, S. R., Baldo, M. V. C., Felício, L. F., \& Canteras, N. S. (2006). A role for the periaqueductal gray in switching adaptive behavioral responses. Journal of Neuroscience, 26, 2583-2589. https://doi.org/10.1523/JNEUROSCI.4279-05.2006

van der Staay, F. J. (2006). Animal models of behavioral dysfunctions: Basic concepts and classifications, and an evaluation strategy. Brain Research Reviews, 52, 131-159. https://doi.org/10.1016/j.brainresrev.2006.01.006

Viana, M. de B., Tomaz, C., \& Graeff, F. G. (1994). The elevated T-maze: A new animal model of anxiety and memory. Pharmacology, Biochemistry \& Behavior, 49, 549-554. https://doi.org/10.1016/0091-3057(94)90067-1

Vianna, D. M. L., Graeff, F. G., Brandão, M. L., \& Landeira-Fernandez, J. (2001). Defensive freezing evoked by electrical stimulation of the periaqueductal gray: Comparison between dorsolateral and ventrolateral regions. Learning \& Memory, 12, 4109-4112. 
Yang, M., Augustsson, H., Markham, C. M., Hubbard, D. T., Webster, D., Wall, P. M., ... Blanchard, D. C. (2004). The rat exposure test: A model of mouse defensive behaviors. Physiology \& Behavior, 81, 465-473. https://doi.org/10.1016/j.physbeh.2004.02.010

Zangrossi Jr, H., \& Graeff, F. G. (2014). Serotonin in anxiety and panic: Contributions of the elevated T-maze. Neuroscience \& Biobehavioral Reviews, 46, 397-406. https://doi.org/10.1016/j.neubiorev.2014.03.007

Zangrossi Jr, H., Viana, M. de B., Zanoveli, J., Bueno, C., Nogueira, R. L., \& Graeff, F. G. (2001). Serotonergic regulation of inhibitory avoidance and one-way escape in the rat elevated T-maze. Neuroscience \& Biobehavioral Reviews, 25, 637-645.

https://doi.org/10.1016/S0149-7634(01)00047-1 